\title{
Efficiency determination of amplitude decay of pressure fluctuation of circulating fluid with the help of a multi-stage piston-type downhole compensator
}

\author{
Minnivaleev Timur Nailevich \\ Ufa State Petroleum Technological University, \\ Branch of the University in the City of Oktyabrsky, Russian Federation \\ timxn@yandex.ru
}

\begin{abstract}
Drilling mud circulation is performed by means of positive piston-type mud pumps which cause nonuniform flow in the drill column. Fluctuations of circulation rate and mud pressure result in increasing the dynamics of the drilling tool, early wear and operating trouble of the drill bit, reservoir depressurization, unstable running and breakdowns of downhole drilling motors, operating life reduction of pump components. Delivery line is under the influence of high pressure with a significant value of its fluctuation which causes negative consequences. The paper is devoted to the developed downhole hydromechanical compensator of pressure fluctuation of circulating fluid mounted into the assembly of drilling string bottom. Moreover, it focuses on the description of the laboratory bench for testing the compensator and the obtained results.
\end{abstract}

Key words - pressure fluctuation, circulating fluid, downhole compensator, pressure amplitude decay, mud pump.

\section{INTRODUCTION}

It is known that oil recovery ratio from the earth depths is defined by geological deposit aspects and technologies applied for reservoir and production engineering. Among technologies well spacing which mainly depends on the drilling cost is of great importance [1-5].

Drilling oil-and-gas wells is a complicated process accompanied by inevitable occurrence of oscillation processes of drilling tools and circulating fluid which, in their turn, have a considerable influence on economic performance of drilling in whole [6].

Due to its design features the positive piston-type mud pump is a source of violent fluctuation of circulation rate and mud pressure [7-8]. In the conditions when the mean level of mud pressure reaches $10 \mathrm{MPa}$ and more, nonuniformity of circulating fluid motion causes not only pressure fluctuation in the hydraulic system but also some extra oscillation of the drilling string with the same frequency [9]. Pressure waves in the drilling mud column cause fluctuations in angular velocity, hydraulic force, torque and power of the downhole drilling motor shaft, excite longitudinal and torsional oscillations of the downhole drilling motor and all drilling tools. Large frequency fluctuation of shaft speed results in the fact that the safe operating area of downhole drilling motors becomes narrower at the level of low end speed, which causes frequent stops of downhole drilling motors under the increased load on the drill bit and, especially, when drilling elastoplastic rocks [10].

\section{METHODS AND MATERIALS}

The obtained results, mentioned in the paper, are based on the analysis of literature review, empirical and analytical methods. While processing the data obtained as a result of laboratory testing, analysis techniques with using personal computers and up-to-date software products have been applied.

\section{METHOD CONTENT AND ASSESSMENT OF ITS EFFICIENCY}

In order to reduce the fluctuation of circulation rate and mud pressure while drilling, a downhole hydromechanical compensator, which is shown in Figure 1, has been developed [11].

The compensator is mounted into the drilling tool configuration by means of crossover subs and tool-joint threads (16 and 17). The pulsating fluid goes into the compensator, puts pressure on the pistons $(5,6,7)$ and thereby compresses the spring in the piston underside area connected with the annulus by end-to-end channels $(8,9,10)$. Thus, it results in pressure amplitude decay of circulating fluid in the cavity of the drilling tool.

In order to conduct laboratory testing of the designed downhole hydromechanical compensator, a laboratory bench was developed at the Chair of Oil and Gas Field Machinery and Equipment of the Branch of Ufa State Petroleum Technical University in the City of Oktyabrsky (Fig. 2).

The laboratory bench is a closed circulation system consisting of a tank (1) filled with fluid; a mud pump $9 \mathrm{MGr}$ (2) providing fluid delivery; a hydromechanical compensator (3); a pressure sensor (6); lock units (5 and 9); a data gateway (7); a computer (8). 


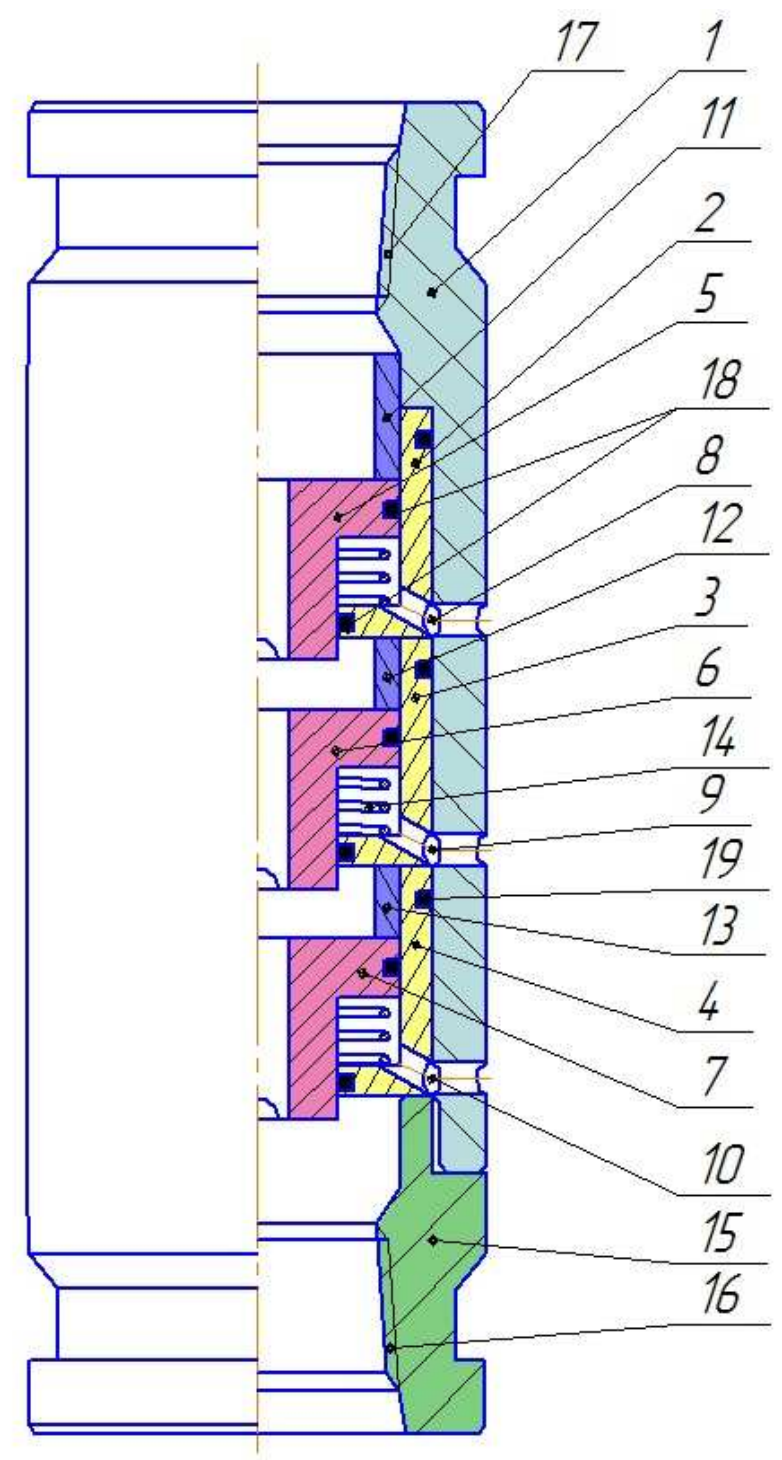

1 - body; 2, 3, 4-partitions; 5, 6, 7 - pistons; 8, 9, 10 - end-to-end channels with annulus; 11, 12, 13 - bushings; 14 - springs; 15 - crossover sub; 16,17 tool-joint threads; 18,19 - seals

Fig. 1. A downhole hydromechanical compensator

The aims of the laboratory testing of the hydromechanical compensator are:

- To measure the pressure amplitude occurring in the pipeline while the mud pump is running at the moment of injection;

- To evaluate the degree of pressure fluctuation damping by the hydromechanical compensator while the mud pump is running.

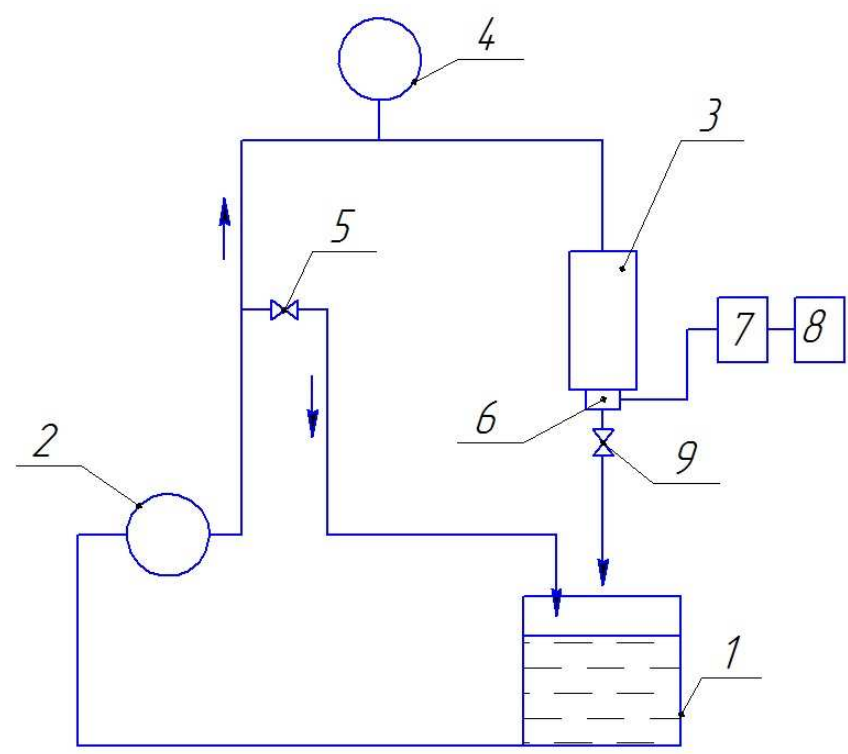

1 - a tank; 2 - a mud pump 9 MGr; 3 - a hydromechanical compensator; 4 a manometer; 5,9 - lock units; 6 - a pressure sensor; 7 - a data gateway GW485.01 (converter RS-232/RS-485); 8 - a computer

Fig. 2. A bench design for hydraulic testing of the hydromechanical compensator for fluid pressure fluctuation

The bench allows testing the operation of the hydromechanical compensator. The mud pump (2) delivers fluid from the tank into the circulation system. The fluid goes through the hydromechanical compensator where pressure oscillation damping happens. After that the fluid goes back to the tank. Fluid pressure fluctuation is measured with the help of the pressure sensor when it leaves the compensator. By using the lock unit (5) it is possible to change fluid delivery which goes through the compensator. By using the lock unit (9) the required working pressure is adjusted in the hydraulic system.

Having removed the damping elements from the compensator body it is possible to measure the pressure fluctuation of circulating fluid in the same way.

When developing the test section of the bench the following statements were kept in mind. When the drilling tool runs, pressure fluctuations occur but discrete pressure measurements taken after a long period of time cannot characterize the process. Consequently, it is necessary to measure pressure more often during the definite period of time [12].

In order to record the pressure rate which is measured at different times in the hydraulic system of the laboratory bench it is important for the measuring system of the pressure sensor to show short-term lag. Otherwise, it will misrepresent the measuring. Strain-gage sensors which natural frequency is within 330-1000 Hertz meet the given requirement [13].

The operating principle of strain transducers lies in changing the electrical resistance of conductors fixed on the elastic member (membrane) depending on their deformation caused by the process pressure [14]. 
In contrast with analog amplitude-modulated signals, the digital signals are transmitted for long distances practically noise free. Besides the possibility to transmit data noise free, digital signals have other advantages over the analog ones: memorizing simplicity, ease of use, a possibility to use a computer to process large amounts of data. It is therefore appropriate to convert analog signals into digital ones as early as possible.

In order to record the fluid pressure change during laboratory testing, sensors of the PDI-01 type produced by group of companies "Grant" were used. The sensor was connected to the computer by means of the data gateway GW485.01 (converter RS-232/RS-485), where the logger Manograph was run.

The performance specifications of the applied pressure transducer are shown in Table 1.

TABLE I. THE PERFORMANCE SPECIFICATIONS OF THE PRESSURE TRANSDUCER PDI-01

\begin{tabular}{|l|c|}
\hline \multicolumn{1}{|c|}{ Parameter } & Value \\
\hline $\begin{array}{l}\text { Maximum scale value of excess } \\
\text { pressure }\end{array}$ & $16 \mathrm{MPa}$ \\
\hline $\begin{array}{l}\text { Limits of error, \% from upper } \\
\text { limit }\end{array}$ & \pm 0.25 \\
\hline $\begin{array}{l}\text { Measuring resolution } \\
\text { (implemented in software) }\end{array}$ & 0.02 \\
\hline Output signal & RS-485 \\
\hline Overall dimensions, mm & $113 \times 53$ \\
\hline Weight, kg, not more & 0.2 \\
\hline
\end{tabular}

As a result of testing, compression curves have been obtained; some of them are represented in Figures 3 and 4.

Figure 3 shows the results of measuring pressure change in the hydraulic system of the laboratory bench at medium pressure of $3 \mathrm{MPa}$. Looking at the figure it is seen that peakto-peak amplitude of pressure fluctuation in the system without damping stages in the compensator reaches $1.5 \mathrm{MPa}$ and it is a considerable value. With damping stages adjusted in the compensator, peak-to-peak amplitude of pressure fluctuation reaches approximately $0.8 \mathrm{MPa}$.

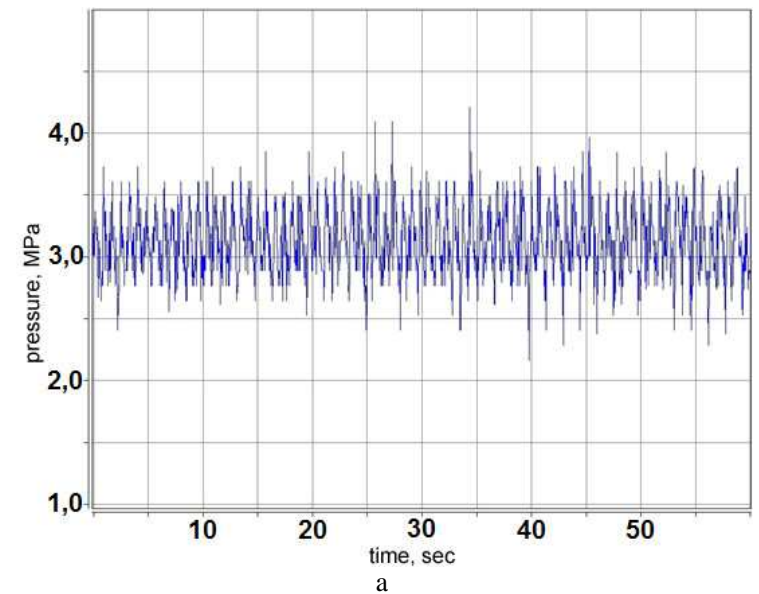

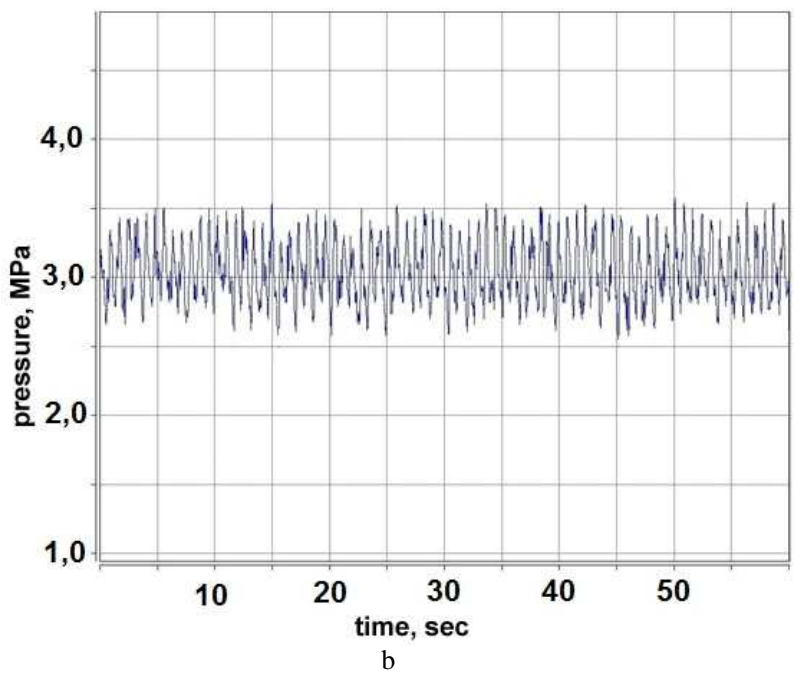

Fig. 3. A compression curves at medium pressure of $3 \mathrm{MPa}$ : a - without compensator, $\mathrm{b}$ - with compensator
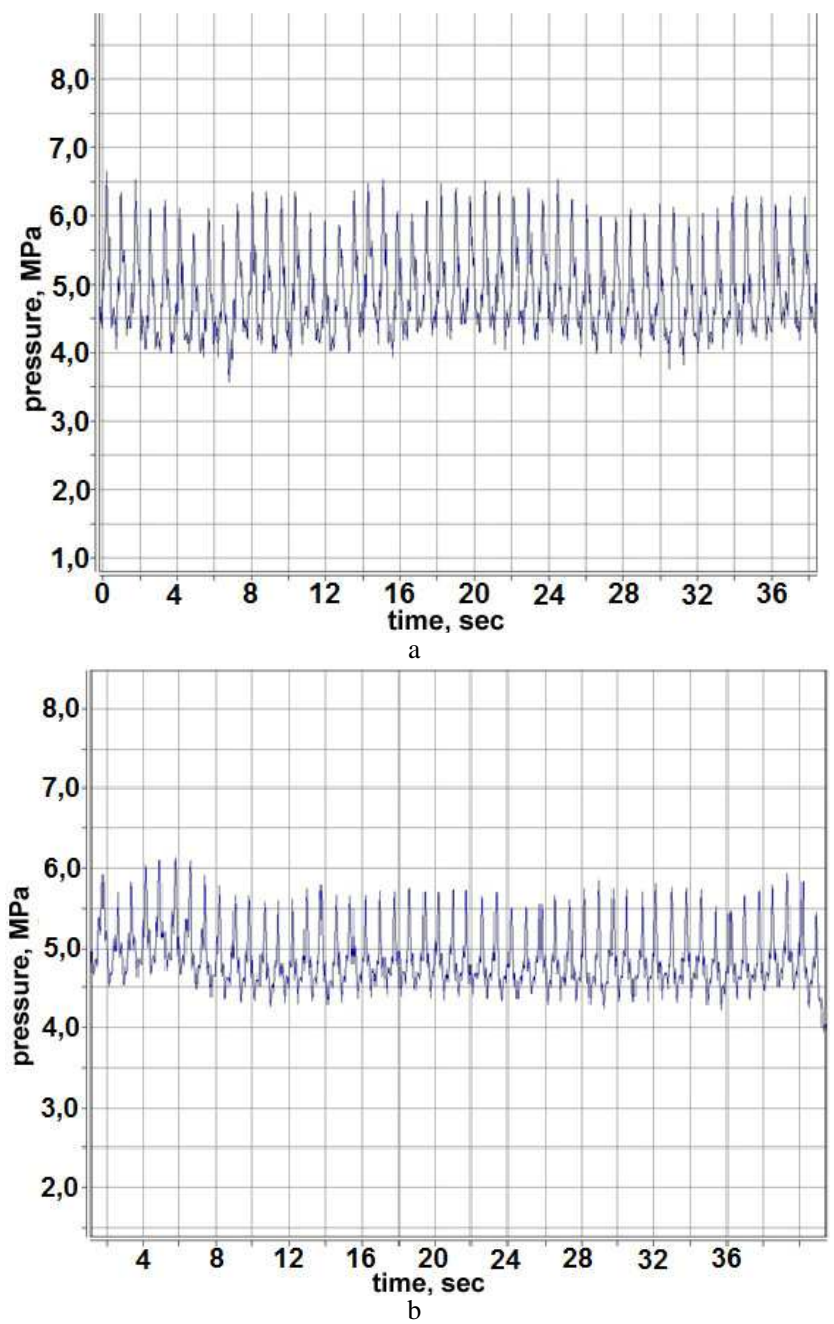

Fig. 4. A compression curves at medium pressure of $5 \mathrm{MPa}$ : a - without compensator, $\mathrm{b}$ - with compensator 
The similar results were obtained when the pressure in the hydraulic system of the laboratory bench was fixed at $5 \mathrm{MPa}$ (Fig.4).

Thus, the conducted bench study of the hydromechanical compensator confirms its working efficiency. In particular, when fixing medium pressure at 3 and $5 \mathrm{MPa}$ in the hydraulic system, fluid pressure fluctuations occur with peak-to-peak amplitude equal to 1.5 and $2.5 \mathrm{MPa}$ respectively. When mounting the hydromechanical compensator on the laboratory bench, at similar medium pressures in the hydraulic system peak-to-peak amplitude of pressure fluctuation reduced to 0.8 and 1.5 MPa respectively. Similar results were obtained when in the hydraulic system the pressure was fixed at other values.

\section{CONCLUSION}

1. In order to reduce the negative effect of pressure fluctuation of circulating fluid on the process of borehole drilling it was suggested to apply a construction of a multistage downhole hydromechanical compensator which is patented.

2. Mounting a downhole hydromechanical compensator on the laboratory bench allows reducing pressure fluctuations practically in two times.

3. The positive results of laboratory testing of the developed equipment confirm its high operating efficiency.

\section{References}

[1] V.N. Polyakov, Yu.V. Zeigman, Yu.A. Kotenev, V.V. Mukhametshin, Sh.Kh. Sultanov, and A.P. Chizhov, "System solution for technological problems of well construction completion," (in Russian), Nanotechnologies in Construction, vol. 10, no. 1, pp. 72-87, 2018. DOI: 10.15828/2075-8545-2018-10-1-72-87.

[2] V.V. Mukhametshin, "Efficiency estimation of nanotechnologies applied in constructed wells to accelerate field development," Nanotechnologies in Construction, vol. 10, no. 1, pp. 113-131, 2018. DOI: 10.15828/20758545-2018-10-1-113-131.
[3] V.Sh. Mukhametshin, "Dependence of crude-oil recovery on the well spacing density during development of low-producing carbonate deposits," Oil Industry, no. 12, pp. 26-29, 1989.

[4] R.T. Akhmetov, V.V. Mukhametshin, A.V. Andreev, and Sh.Kh Sultanov, "Some testing results of productive strata wettability index forecasting technique," SOCAR Proceedings, no. 4, pp. 83-87, 2017. DOI: $10.5510 / O G P 20170400334$.

[5] V.V. Mukhametshin and R.R. Kadyrov, "Influence of nanoadditives on mechanical and isolating properties of cement-based compositions," (in Russian), Nanotechnologies in Construction, vol. 9, no. 6, pp. 18-36, 2017. DOI: $10.15828 / 2075-8545-2017-9-6-18-36$.

[6] T.N. Minnivaleev, "Desighing of the compensator for protecting pipelines and equipment from pressure fluctuation and hydraulic impacts," Problems of Gathering, Treatment and Transportation of Oil and Oil Products, no. 4 (90), pp. 164-168, 2012.

[7] M.S. Gabdrakhimov, T.N. Minnivaleev and R.M. Galimov, "Analysis of oil wells drilling in Aznakaevsky drilling department of "Burenie, ltd." ", Construction of oil and gas wells on land and sea, no. 5, pp. 8-11, 2013.

[8] M.Y. Khabibullin, R.I. Suleimanov, D.I. Sidorkin and I.G. Arslanov, "Parameters of damping of vibrations of tubing string in the operation of bottomhole pulse devices", Chemical and Petroleum Engineering, vol. 53, no. 5-6, pp. 378-384, 2017.

[9] CB Guan, ZX Jiao, and SZ He, "Theoretical study of flow ripple for an aviation axial-piston pump with damping holes in the valve plate," Chinese journal of aeronautics, vol. 27, no. 1, pp. 169-181, 2014.

[10] M. Ivantysynova, "The piston cylinder assembly in piston machines-A long journey of discovery [C]," Proceedings of 8th IFK International Conference on Fluid Power, Dresden, Germany: Hidrostaticni pogoni, pp. 307-332, 2012.

[11] M.S. Gabdrakhimov, T.N. Minnivaleev, R.I. Suleymanov, and L.M. Zaripova, Patent 2516734 RF, MPK F16L 55/04, "Flush Water Compensator," Declared 28.01.2013, Publushed 20.05.2014.

[12] L.G. Akhmetov, A.Z. Ibatova, A.L. Popov, K.N. Yagafarova, and M.A. Stavruk, "Using on compressed gas vehicles combined injection of fuels," Int. J. of Applied Engineering Research, no. 12 (24), pp. 15592-15598.

[13] N.Y. Golovina, L.G. Akhmetov, A.N. Vikharev, and I.G. Arslanov, "Analysis on compressor blading conditions of helicopter's gas-turbine engine working in polluted environment," International Journal of Applied Engineering Research, vol. 12, no. 3, pp. 293-296, 2017.

[14] F. Canbulut, C. Sinanoglu, and E. Koc, "Experimental analysis of frictional power loss of hydrostatic slipper bearings [J]," Industrial lubrication and Tribology, no. 61(3), pp. 123-131, 2009. 